\title{
(息)
}

Citation:

Woodall, J and Dixey, R and South, J (2013) Prisoners' perspectives on the transition from the prison to the community: Implications for settings-based health promotion. Critical Public Health, 23 (2). 188 - 200. ISSN 0958-1596 DOI: https://doi.org/10.1080/09581596.2012.732219

Link to Leeds Beckett Repository record:

https://eprints.leedsbeckett.ac.uk/id/eprint/94/

Document Version:

Article (Accepted Version)

The aim of the Leeds Beckett Repository is to provide open access to our research, as required by funder policies and permitted by publishers and copyright law.

The Leeds Beckett repository holds a wide range of publications, each of which has been checked for copyright and the relevant embargo period has been applied by the Research Services team.

We operate on a standard take-down policy. If you are the author or publisher of an output and you would like it removed from the repository, please contact us and we will investigate on a case-by-case basis.

Each thesis in the repository has been cleared where necessary by the author for third party copyright. If you would like a thesis to be removed from the repository or believe there is an issue with copyright, please contact us on openaccess@leedsbeckett.ac.uk and we will investigate on a case-by-case basis. 
Prisoners' perspectives on the transition from the prison to the community:

implications for settings-based health promotion 


\title{
Prisoners' perspectives on the transition from the prison to the community: implications for settings-based health promotion
}

\begin{abstract}
Through qualitative exploration with soon-to-be-released men in three prisons in England, this paper examines the difficulties that prisoners envisage on returning back to community settings; entering other settings such as workplaces; and the implications the transition may have for their health. Interviews and focus groups were conducted with thirty-six prisoners, some of whom were convicted of sexual offences and based on a vulnerable prisoner unit (VPU). While not all prisoners offered the information, approximately two-thirds of the sample had offended previously. The transition that individuals make from the prison setting to the community can be potentially complex and often detrimental to health.

Accommodation issues were forecast as a major concern for those men without family ties. Temporarily residing with friends or living in hostel residences were viable options for many prisoners, but both had drawbacks which could increase the probability of engaging in substance misuse. Resettlement issues were perceived to be more difficult for sex-offenders; their 'identity' provided an additional burden which created further re-integration difficulties. Employment opportunities, for example, were predicted to be drastically reduced as the men had signed the sex-offenders' register. The paper suggests that opportunities for successful transition could be enhanced by a more 'joined-up' settings perspective and proposes that a settings-based approach to health promotion, which emphasises the synergy between social settings and addressing wider determinants of health, should be applied to prisons to reduce, rather than exacerbate, inequalities.
\end{abstract}


Key words: Prison health, settings-approach, anticipated transition, health promotion, health promoting prison. 


\section{Prisoners' perspectives on the transition from the prison to the community: implications for settings-based health promotion}

\section{Introduction}

The 'settings approach' has become mainstreamed in health promotion as a way to improve health in the myriad of places where people live, work, and play out their lives (WHO 1986). The premise of a settings approach is that investments in health, and the wider determinants of health, are made in a variety of places and the promotion of health is therefore positioned as a responsibility for all social settings. It tends to be presumed that people live their lives in a plurality of settings; however, a criticism of settings approaches is that some people are not found in typical 'settings' (Green et al. 2000). Thus out-of-school youth, the unemployed, those living on the margins of communities, for instance, are classed as 'hard to reach'. Secondly, it tends to be accepted that transition from one setting to another is a manageable and normative aspect of life, such as from primary to secondary school, or from work to retirement. Within the setting of the prison, offenders have to manage the transition to prison life, and later, the transition back to the community. This might be a permanent move, or in the case of recidivists, a temporary one. The aim of this paper is to explore soon-to-be released prisoners' perspectives and forecasts on transitioning from prison back to the community, with the aim of furthering understanding of the health promoting potential of the prison setting.

As of March 2012, the prison population of England and Wales stood at 87,787 (Ministry of Justice 2012), one of the highest imprisonment rates in Europe (International Centre for Prison Studies 2009). Between 1995 and 2009 the number of people in prison increased by 32,500, equating to an overall growth of $66 \%$ (Ministry of Justice 2009). . There are 
approximately 40 prisoners in England and Wales serving 'whole life' tariffs (Prison Reform Trust 2011), essentially those individuals who are never to be released back into society and thus will live the remainder of their lives in only one setting. In contrast, the majority of the prison population are serving short sentences and most are released back into society within 12 months from sentencing. The challenge of making the successful transition has never, therefore, affected so many prisoners and their families as at the present time.

International studies indicate that the transition from the prison back to the community is often difficult and disordered. In the USA the process has been described as 'deeply flawed' (Mitchell et al. 2002), with consequent deleterious effects on health and well-being. For example, Binswanger et al. (2007) demonstrated that during the first two weeks after release, the risk of death among former US prisoners was 12.7 times higher than community residents of the same age, sex, and race. Starker still, Farrell and Marsden's (2008) research in England and Wales showed that male prisoners were 29 times more likely to die during the week following release compared to the general population. The cause of death soon after release from prison is often linked to drug overdoses. Furthermore, on release from prison many men engage in other risky health-behaviours (e.g. hazardous alcohol consumption, unprotected sex) which potentially jeopardise their and others' health (Stewart 2008). These findings overall support the notion that the transition from the prison to the community is a "health depleting experience" (Burgess-Allen et al. 2006, p.300). This conforms to the literature on transitions, which suggest that any transition can be stressful, whilst a successful transition is one where individuals come to terms with, and learn to manage, discontinuities (Tobbell and O’Donnell 2005). Successful transitions are important to health and wellbeing and certain factors mediate the impact of transitions, including social and practical support from significant others, personality, coping abilities and economic circumstances (George 
1993). The transition literature and theory provide pointers as to how to manage any transition successfully, but these lessons appear to be applied less-well in the criminal justice system.

Released prisoners are more likely to return to heavily populated urban localities, and to reenter communities that are poor, overburdened with substandard housing, and with high rates of unemployment (Jacobi 2005, Willmott and van Olphen 2005, Bonhomme et al. 2006, Williams 2007). These communities also present disproportionate rates of poor health and moreover, the instability of these localities frequently means that there is a profound impact on community and family cohesion (Whitehead 2006). Current policy advocates that planning between mental health services and drug and alcohol services should take place for prisoners on release (Department of Health 2009). Undoubtedly, these services are important but released prisoners face a myriad of other challenges. Some argue that a more holistic conceptualisation of improving ex-prisoner health is needed, including a greater understanding of the determinants of ex-prisoner health (Burgess-Allen et al. 2006). However, this holistic understanding has been relatively underexplored and there is a particular dearth of qualitative research exploring the transition the prison population faces when reintegrating back into the community. Indeed, Mullen et al. (1995) point out the limitations in our understanding concerning the relationships between 'settings' for health in this case between the prison 'setting' and the community 'setting'.

\section{Methodology}

The findings reported here emerged from a wider study which examined the concept and practice of the 'health promoting prison' and how control and choice - values central to the health promotion discourse - are applied to the context of imprisonment (Woodall 2010). 
The study took an interpretive approach which recognised that the social world is constructed by people's meanings and motives and that knowledge is created by human beings as they engage with the world they are interpreting (Crotty 1998). To capture this, in-depth interviews and focus groups were conducted with soon-to-be released male prisoners from three institutions in England. This methodological approach was particularly important, as often prisoners' views and accounts are relatively unheard during research processes (Ammar and Weaver 2005, Hek 2006). These prisoners were based in category-C institutions which means that the men could not be trusted in open prison conditions but were unlikely to have the ability or resources to make a determined escape attempt (Leech and Cheney 2002). The difficulty of 'outside' researchers entering prisons has been very well documented (King 2000, Noaks and Wincup 2004, King and Wincup 2008) and this study was not exempt from these challenges. Access was negotiated through the Offender Health Research Network and senior governors in each of the prisons after the aims of the study had been presented and ethical approval was given by an NHS Research Ethics Committee.

Once permission was granted to conduct the research, the process used to select prisoners was important for obtaining a sample which would represent the 'maximum variation' (Patton 2002) of experiences held by those within the prison setting. This variation included demographic features, offence types, experiences of prison life (first time offenders, chronic recidivists) and sentence lengths. In each prison, distinct geographical areas (mainly residential wings) were chosen for recruiting individuals into the research. These areas were determined in meetings with the primary gatekeepers and governors in each prison. After the areas had been identified and agreed, participants were recruited into the study using recruitment materials designed to draw attention to the research and provide some preliminary information as to its overall aims and general purpose. 
Although physically accessing the prison allowed the research to get underway, the process of acquiring acceptability was fundamental if any meaningful data were to be collected at the research sites. Throughout the process of rapport building and fieldwork, it was important that the researcher made apparent the detachment he had from the Prison Service. This division was important in order to offer impartiality and establish a sense of trust with prisoners that may have chosen to become research participants. Not holding prison keys, for instance, allowed the researcher to symbolically distance himself from the prison staff and authorities (King 2000).

A total of thirty-six prisoners agreed to participate including thirteen men on a vulnerable prisoner unit (VPU) convicted of sexual offences and segregated from the main prison population for their own safety. All participants were provided with participant information and gave written consent prior to data collection. Nineteen prisoners took part in one to one in-depth interviews lasting between one and two hours and a further seventeen prisoners participated in a total of four focus group discussions lasting, on average, one and a half hours. Prison staff respected the prisoners' freedom to express themselves openly, as no staff members were present during interviews or focus groups.

\section{Ethical considerations}

Prisoners are a vulnerable sub-section of the population and extreme sensitivity was required when conducting research (Smith and Wincup 2002). One particular issue concerned voluntary consent, as the extent to which those held in captive conditions can provide consent has been debated and contested (Freudenberg 2007). Prisoners are usually inclined to 
contribute to research activities: this is largely underpinned by their desire to occupy their time within the institution, to alleviate boredom and to spend time talking to someone interested in them as individuals (Quraishi 2008). This can mean that prisoners may become drawn into research with only scant knowledge of what participation may entail. Throughout this study, it was made explicit to prisoners that engagement with research activities held no advantage or disadvantage to them or their period of custody within the institution. In addition, the right to withdraw from the study, without providing any reason, was made clear.

\section{Data analysis}

Although it is customary to audio record interviews, two prison governors did not permit recording equipment in their prisons due to security concerns. This is not uncommon in prison-based research (Schlosser 2008). Where audio recording was prohibited, elements raised by participants were jotted down in the form of key words and phrases and written up in more detail immediately after the interview had finished.

The use of thematic networks, as advocated by Attride-Stirling (2001), was adopted as a systematic way of organising the analysis. Further details of how this analytical approach was applied to the data can be found elsewhere (Woodall 2010). In summary, thematic network analysis builds on key features which are predominant in other forms of qualitative data analysis, but is unique in that the aim of the analysis is to construct web-like matrices. This provides insight into the researcher's explicit processes from generating interpretation and theory from text and transcripts. Thematic networks systematically organise initial codes into basic themes. Themes often emerged from the data itself (inductive) or from prior theoretical understandings of the area under study (Boyatzis 1998). Although researcher judgement is crucial to determining thematic categories, Ryan and Bernard (2003) have 
proposed techniques for arriving at a theme. Repetition of key issues in the raw data, for example, is one of the simplest forms of theme identification. Once basic themes are identified they are grouped to form organising themes and then an overarching global theme is produced which succinctly encapsulates aspects of the data. NVivo 7 software was used to aid the analysis.

\section{Findings}

Although in-depth details concerning a prisoner's offence, their social background and their previous criminal activity were not routinely covered, many men provided extensive autobiographical reflections on their life, their pre-prison circumstances and their criminal activities. While not all prisoners offered the information, approximately two-thirds of the sample reported offending previously. The majority of interviewees on the VPU were firsttime offenders. The following section presents the salient themes from the data relating to concerns about transition.

\section{Prisoners unprepared for release}

There was an overwhelming apprehension of re-integrating back into the community for several prisoners. These concerns about release occurred at different time points throughout prisoners' sentences and were often dependent upon past prison experiences and the level of family support they were expecting post-release. Chris, for example, was a year away from release but recognised the substantial problems he would face: 
I've got twelve months left, and I'm already thinking about what I'm going to do when I get out, it can be quite scary. I'm thinking, what the fuck am I going to do, am I going to go back to what I was doing, selling this and selling that.

Several prisoners suggested that they were not being entirely equipped during their sentence with the skills and resources necessary for successful reintegration. Once released from prison, many suggested that they would expect to feel a sense of helplessness, as Aaron noted: "there is nothing in place for when you are getting out of prison". However, those men who had served a series of previous sentences and those with strong family connections seemed unperturbed by the thought of resettling back into their home communities. Simon, for example, was planning to live back with his family:

I've got friends and family so hopefully I'll be sorted. I have a close knit family behind me.

\section{No fixed abode}

Finding suitable accommodation after prison was a primary concern for many men. Prisoners discussed a variety of accommodation options that were available to them on their release. Some reported that they would be returning to their family home, some had arranged temporary accommodation with friends, whilst others anticipated spending time in probation premises (predominantly hostels). Many prisoners, however, were less fortunate and had no firm plans as to where they would stay once released.

Those men who anticipated staying in hostels on their release were not relishing the prospect of this environment. Some regarded the hostel as an extension of the prison, as it had 
numerous rules and regulations (like night-time curfews) and others commented on the undesirable residents that often shared this accommodation:

You are going to another prison where there are more rules and you are getting mixed with all the scum, people that are taking drugs, sex-offenders... and you have to be in at ten o'clock at night. (Terry)

Hostels were perceived as being potentially damaging environments for those who had been treated for substance misuse in prison. Typically, prisoners assumed that these settings were: "full of people that are using drugs" (Gaz).

Those who received drug treatment whilst in prison were concerned about living in a hostel and the possibility of associating with drug-using residents. Rob felt that this environment would undo the positive rehabilitation work which had been done in prison. Other prisoners held comparable viewpoints and reflected on the limited control they had over their lives after release:

Well I've been in jail for four years this time and all the good work I've done in prison when I get out it could just all go away because I have nothing to go out to. (Rob)

Whilst staying with friends was a viable alternative to living in a hostel, this held drawbacks. Many suggested that their friends also had criminal records which could increase the likelihood of becoming involved in activities detrimental to their resettlement. Aaron, for 
instance, claimed that he would be staying on a friend's sofa and was concerned that he would be encouraged, whilst living there, to take drugs and commit crimes.

Several prisoners suggested that finding permanent accommodation could be the difference between 'staying straight' or re-engaging with drugs and returning to prison. Warren, for instance, wanted to desist from crime but suggested that this was dependant on whether he was able to find suitable accommodation. Without an appropriate place to stay, Warren believed that the likelihood of leading a law-abiding life was unlikely. For some men, their family connections had been severed as a consequence of their imprisonment and so the likelihood of a smooth return to the family home was not always possible. In some cases, this severance was forced upon the family unit (i.e. due to the financial difficulties of visiting the prison) and on others this was a planned separation.

\section{“...living from hand to mouth”}

On release from prison, most men were entitled to a discharge grant to cover their immediate expenses during their release. Several interviewees suggested that the grant, in the region of forty-five pounds, was not sufficient to cover the time between release and receiving benefit payments or gaining employment. Interestingly, this issue was not raised during focus group discussions and perhaps suggests that prisoners felt less comfortable sharing their financial status amongst others. The insufficiency of the discharge payment meant many felt that they had little option but to return to crime:

I'm getting kicked out of here [the prison] basically with nothing, well I get fortyseven quid and they expect that to last you two weeks before you can get any money off the dole. [...]That's why people re-offend you having your forty-seven pounds but 
that's gone in a day or two, you're living from hand to mouth, if you've got nothing you're going to think fuck it if I get caught I get caught. (Terry)

Obtaining employment became vital if prisoners were to reintegrate into the community and desist from crime. Employment was especially necessary if prisoners were to avoid living in hostels and to afford a deposit for a privately rented property. Warren suggested that failure to earn a respectable wage would increase the likelihood of re-engaging in criminal activity, especially drug dealing and acquisitive crime. Some prisoners even preferred to risk selling illicit substances rather than living on low-level benefit payments:

I have worked out there, a proper job like, and I felt better about myself when I had a job, I was proud that I had a job, it gives you a more positive way of thinking, instead of waking up and you've got fuck all, what are you going to do today 'oh I'm going to go to the job centre and then I've got to do this and that' you think oh fuck it, I may as well be back in jail, I may as well take that risk and sell drugs, at least I'm going to be alright while I'm doing it. (Terry)

\section{Troubled identity: being a sex-offender}

According to prisoners on the VPU, resettlement problems were compounded if prisoners had been convicted of sex offences. The perceived stigma and the public anxieties surrounding such individuals created further difficulties which were envisaged to restrict successful reintegration. Those convicted of sex offences were apprehensive at the thought of vigilante action and the possibility of being physically attacked by members of the public who were aware of their crimes. Employment after release, as opposed to accommodation, was the main concern for most men on the VPU. Indeed, many were unconcerned with 
accommodation issues, as these men were generally returning to their privately owned homes after release. Don, however, noted how employment opportunities for sex-offenders were extremely restrictive as they were obliged to sign the sex-offenders register. This prohibited these men from working in specific occupations and with certain groups of the population. Other prisoners were in paid employment prior to their conviction, but felt that they were highly unlikely to be able to return to their previous role.

\section{Discussion}

The study has highlighted the difficulties that prisoners foresee on reintegrating back into their communities after release from prison in three category-C institutions. It emphasises a series of issues, including how prisoners feel unprepared for release, emotionally, practically and financially, and the difficulties they encounter when finding suitable accommodation and employment in the community. These issues have clear health implications, with inadequate and substandard housing having a direct (in terms of physical and mental health) and indirect (in relation to access to services) health impact (Gill and de Wildt 2003), and unemployment potentially being particularly detrimental to the mental health of men (Artazcoz et al. 2004). The study points to an inevitability of prison release where often prisoners had very little to return back to and where the majority were reliant on welfare support. These problems not only raised anxieties and stress levels, but the impending realities of poor accommodation and unemployment would also impact on health through re-engaging with drugs. The findings presented here resonate with those from studies undertaken in other countries, such as Graffam and Shinkfield's (2011) Australian study, which found that those leaving prison were in a poor financial situation, underemployed with variable social support networks. Preparedness is regarded as the first condition of any successful transition and it is clear that the prisoners in this study were under-prepared for release. 
This study was unique in that opportunity was taken to uncover the views of vulnerable prisoners, mainly those convicted of sexual offences, as well as the wider prison population. The issues for the men on the VPU were, in the main, different from the majority of the sample and concerned anxieties around vigilantism and the prospect of unemployment because of their allocation onto the sex-offender's register. These prisoners' viewpoints are supported in the wider literature as in recent times the reintegration of sex-offenders into the community has caused hostile and violent reactions from the public (Farrall et al. 2011). Whether ex-prisoners should be reintegrated 'anonymously' without notifying the wider community is a debate that is on-going, but data here suggests that specific attention and support, in terms of transition back into the community, is required. This suggestion may not gain public support, but there is a wider moral imperative that all offenders are reintegrated into the community appropriately. Furthermore, prior studies reinforce the current findings presented here that those convicted of sexual offences experience more barriers to gaining employment on release than the majority of offenders (Brown et al. 2007). Although offender identity is essentially temporal, in that, in theory, once prisoners have served the sentence passed down from the courts they lose the offender 'label', sex offenders had an identity which was on-going and far more difficult to escape from.

The criminal justice system as a whole is dealing with a socially marginalised group. Within the prison system, many of those being convicted of offences have already been subjected to a lifetime of social exclusion, including poor educational backgrounds, low incomes, meagre employment opportunities, lack of engagement with normal societal structures, low selfesteem and impermanence in terms of accommodation (including bouts of homelessness) and relationships with family members (Levy 2005, Senior and Shaw 2007, Department of Health 
2009, Prison Reform Trust 2009). On leaving the prison, many of these issues will, the men in this sample predicted, remain unresolved.. Of course, issues such as employment and accommodation are major social challenges that are often beyond the remit of prison staff and the prison service, although research does show that prisons can make a major contribution to reforming the lives and improving the health and social circumstances of some people in certain circumstances (Woodall 2010).

One avenue that has potential to address the issues identified is the settings approach, as firstly, settings approaches are holistic, addressing the social determinants of health, and allowing these broader determinants of ex-prisoner health to be considered; secondly it is possible to develop a 'joined-up settings-based approach' where the process of manoeuvring between settings is made more explicit. Although moving between settings is a normal part of everyday life (such as moving between the workplace and the home on a daily basis for the employed), it is a potential threat where the change is more major. Being prepared for these changes has long been recognised as important, but prisons, as more stigmatised settings, have perhaps received less attention. Settings, including prisons, are not discrete entities but are nested within a wider environmental context (Naidoo and Wills 2000, Corcoran and Bone 2007). There is a need, therefore, not to think of a settings approach as fostering "insularity and fragmentation "(Dooris 2006, p.5) amongst organisations, but for the approach to foster synergistic working. Dooris (2012) has referred to this principle as 'horizontal networking' where links are made between settings (e.g. prisons and workplaces). Partnership working is critical to the settings approach (Scriven 2012) and a major challenge to addressing the problems prisoners face on release is to facilitate connections with other settings. Developing partnerships with workplaces, communities, education and training institutions pose several challenges - none more so than marrying together the different cultures and ways of working 
- and moreover, this needs to be prioritised if prisoners are to take more control over their health and its wider determinants. Currently, non-governmental bodies and charities fill the interstitial spaces between the prison setting and the workplace, such as Bounce Back or Working Chance in the UK (rehabilitation charities that train people in employability skills), but such provision is patchy.

These are clear dilemmas faced by the settings-based movement when applied to prison contexts (Woodall and South 2012); however, there is true potential for prisons to operationalize as healthy settings despite health promotion's philosophical values of autonomy, empowerment and partnership working sometimes being incongruous to prison regimes which are disempowering, isolating and security focussed (Whitehead 2006). Whereas much of the policy concern is with recidivism, our concern is with health, and there is a need to understand in more detail the individual pathways to a healthier and more fulfilling post-release life.

To develop prisons that are healthy settings there is a requirement to understand the relationship between settings initiatives and macro-policy. This understanding emphasises the close links between a settings approach and an ecological model of health promotion. The settings approach embraces ecological perspectives as it challenges a reductionist focus on single issues (for example, drug misuse) towards an holistic vision of health and wellbeing which is determined by a interaction of environmental, organisational and personal factors within the places that people live their lives (Dooris 2009). St Leger (1997, p.101), for example, argues that when adopting a settings framework there is a requirement to always stay with "the big picture”. Indeed, if released prisoners are to refrain from re-engaging with drugs and find secure accommodation and employment, then this is ultimately contingent 
upon effective social policy (Knepper 2007). Dooris, for example, encourages healthy settings initiatives to 'connect upwards' to ensure that broader political, economic and social factors are being addressed through political advocacy:

Connecting upwards: A focus on the importance of settings programmes and initiatives working upwards, using advocacy and mediation to ensure action on the underlying determinants of health that may lie outside of their boundaries or immediate remit. (Dooris 2007, p.139)

This particular point is especially pertinent given that prisoners are likely to be disproportionately affected by the current financial recession. Indeed, research conducted prior to the North Atlantic/ European financial meltdown suggested that employment opportunities for ex-offenders was already bleak (Metcalf et al. 2001). The consensus from the general transitions literature is that, to paraphrase, 'a lot of help is needed' plus close links and well-managed co-ordination between the constituent parts of the transition (Evangelou et al. 2008).

Finally, prisons confine a range of individuals who have committed an assortment of offences. Authors are beginning to describe the "kaleidoscopic nature" of prisoners' circumstances and advocating that complexity must be fully understood (Rutherford and Duggan 2009). This study demonstrated that men in category-C prisons vary in their outlook, professional background and social class and that these men experience different types of social exclusion. In the case of sex offenders, the potential of being excluded within the community post-release, and excluded from job opportunities, arise through signing the sex offenders' register. For other prisoners, a lack of income and a lack of family support on reentering the community may potentially jeopardise health, well-being and influence the 
propensity to reoffend. For health promotion in prison it is advocated that a more nuanced appreciation about how issues such as pre-prison biographies interplay to impact on prisoners' negotiation of prison life and their subsequent release into the community is needed. This will require a shift from current practice, which is often geared toward disease prevention and management, toward a focus on broader health determinants of prisoner and ex-prisoner health (de Viggiani 2006).

\section{Conclusions}

This aim of this paper was to gain insight from soon-to-be released prisoners of the transition they envisaged from prison back into the community. The study set out to illuminate the issues from the prisoners' perspective in three category- $\mathrm{C}$ institutions and not necessarily to gain generalisable findings. Future research should, therefore, examine whether these issues apply in other populations, such as women prisoners, young offenders and men in different security level prisons. This study focussed on prisoners' anticipated transition and did not follow-up participants in the community after their release to determine their actual transition. Despite the potential practical and ethical dilemmas associated with this, future research may consider a study design that attempts to capture this important data. The findings from this study suggest that prisoners may face multiple challenges on release from prison which have implications for their health and well-being and the likelihood of reoffending in the future. There is a need to understand what a 'successful transition' would look like, and what its ingredients are.

Tackling prisoners' health and enabling them to take control over the determinants that influence their health is a difficult and complex process requiring the issue to be framed from a multidisciplinary perspective. The research gives a clear indication on the need for better 
articulated relationships 'between settings' (Mullen et al. 1995) and we suggest that a settings approach can bear fruit in producing smoother transitions.

\section{Acknowledgements}

The authors wish to acknowledge the prison governors who allowed their establishments to be involved in the research. Furthermore, the authors would like to thank the prisoners who took the time to share their views and participate in the study.

This study was part of a PhD studentship funded by Leeds Metropolitan University.

\section{References}

Ammar, N.H. \& Weaver, R.R., 2005. Restrained voices: female inmates' views of health services in two ohio prisons. Women \& Criminal Justice, 16 (3), 67-89.

Artazcoz, L., Benach, J., Borrell, C. \& Cortes, I., 2004. Unemployment and mental health: Understanding the interactions among gender, family roles, and social class. Journal of American Public Health, 94 (1), 81-88.

Attride-Stirling, J., 2001. Thematic networks: An analytic tool for qualitative research. Qualitative Research, 1 (3), 385-405.

Binswanger, I.A., Stern, M.F., Deyo, R.A., Heagerty, P.J., Cheadle, A., Elmore, J.G. \& Koepsell, T.D., 2007. Release from prison - a high risk of death for former inmates. New England Journal of Medicine, 356 (2), 157-165.

Bonhomme, J., Stephens, T. \& Braithwaite, R., 2006. African-american males in the United States prison system: impact on family and community. The Journal of Men's Health \& Gender, 3 (3), 223-226. 
Boyatzis, R.E., 1998. Transforming qualitative information. Thematic analysis and code development London: Sage.

Brown, K., Spencer, J. \& Deakin, J., 2007. The reintegration of sex offenders: barriers and opportunities for employment. The Howard Journal of Criminal Justice, 46 (1), 3242.

Burgess-Allen, J., Langlois, M. \& Whittaker, P., 2006. The health needs of ex-prisoners, implications for successful resettlement: a qualitative study. International Journal of Prisoner Health, 2 (4), 291-301.

Corcoran, N. \& Bone, A., 2007. Using settings to communicate health promotion. In Corcoran, N. ed. Communicating health. Strategies for health promotion. London: Sage, 117-138.

Crotty, M., 1998. The foundation of social research London: Sage.

De Viggiani, N., 2006. A new approach to prison public health? Challenging and advancing the agenda for prison health. Critical Public Health, 16 (4), 307-316.

Department of Health, 2009. Improving health, supporting justice: The national delivery plan of the health and criminal justice programme board. London.

Dooris, M., 2006. Health promoting settings: future directions. Promotion \& Education, 13 (1), 4-6.

Dooris, M., 2007. Healthy settings: past, present and future. Unpublished PhD thesis. Deakin University.

Dooris, M., 2009. Holistic and sustainable health improvement: the contribution of the settings-based approach to health promotion. Perspectives in Public Health, 129 (1), 29-36. 
Dooris, M., 2012. The settings approach: looking back, looking forward In Scriven, A. \& Hodgins, M. eds. Health promotion settings: principles and practice. London: Sage, 17-34.

Evangelou, M., Taggart, B., Sylva, K., Melhuish, E., Sammons, P. \& Siraj-Blatchford, I., 2008. What makes a successful transition from primary to secondary school? London.

Farrall, S., Hough, M., Maruna, S. \& Sparks, R., 2011. Escape routes: contemporary perspectives on life after punishment London: Routledge.

Farrell, M. \& Marsden, J., 2008. Acute risk of drug related death among newly released prisoners in England and Wales. Addiction, 103 (2), 251-255.

Freudenberg, N., 2007. Health research behind bars: a brief guide to research in jails and prisons. In Greifinger, R.B., Bick, J. \& Goldenson, J. eds. Public health behind bars. From prisons to communities. New York: Springer, 415-433.

George, L.K., 1993. Sociological perspectives on life transitions. Annual Review of Sociology, 19, 353-373.

Gill, P. \& De Wildt, G., 2003. Housing and health. The role of primary care Oxford: Radcliffe Medical Press.

Graffam, J. \& Shinkfield, A.J., 2011. The life conditions of Australian ex-prisoners: an analysis of intrapersonal, subsistence, and support conditions. International Journal of Offender Therapy and Comparative Criminology, DOI: 10.1177/0306624X11415510.

Green, L.W., Poland, B.D. \& Rootman, I., 2000. The settings approach to health promotion. In Poland, B.D., Green, L.W. \& Rootman, I. eds. Settings for health promotion. Linking theory and practice. Thousand Oaks: Sage, 1-43.

Hek, G., 2006. Unlocking potential: Challenges for primary health care researchers in the prison setting. Primary Health Care Research and Development, 7, 91-94. 
International Centre for Prison Studies, 2009. Entire world - prison population rates per 100,000 of the national population [online]. Kings College. Available from: http://www.prisonstudies.org/

Jacobi, J.V., 2005. Prison health, public health: obligations and opportunities. American Journal of Law \& Medicine, 31 (4), 447-478.

King, R.D., 2000. Doing research in prisons. In King, R.D. \& Wincup, E. eds. Doing research on crime and justice. Oxford: Oxford University Press, 285-312.

King, R.D. \& Wincup, E., 2008. The process of criminological research. In King, R.D. \& Wincup, E. eds. Doing research on crime and justice. 2nd ed. Oxford: Oxford University Press, 13-44.

Knepper, P., 2007. Criminology and social policy London: Sage.

Leech, M. \& Cheney, D., 2002. Prisons handbook Winchester: Waterside Press.

Levy, M., 2005. Prisoner health care provision: reflections from Australia. International Journal of Prisoner Health, 1 (1), 65-73.

Metcalf, H., Anderson, T. \& Rolfe, H., 2001. Barriers to employment for offenders and exoffenders: Part one. Leeds.

Ministry of Justice, 2009. Story of the prison population: 1995-2009. London.

Ministry of Justice, 2012. Population and capacity briefing for Friday 02/03/2012. London.

Mitchell, C., Parent, D.G. \& Barnett, B., 2002. Transition from prison to community initiative. Washington.

Mullen, P.D., Evans, D., Forster, J., Gottlieb, N.H., Kreuter, M., Moon, R., O'Rourke, T. \& Strecher, V.J., 1995. Settings as an important dimension in health education/promotion policy, programs, and research. Health Education Quarterly, 22 (3), 329-345. 
Naidoo, J. \& Wills, J., 2000. Health promotion: foundations for practice, Second ed. London: Bailliere Tindall.

Noaks, L. \& Wincup, E., 2004. Criminological research. Understanding qualitative methods London: Sage.

Patton, M.Q., 2002. Qualitative research \& evaluation methods, 3rd ed. Thousand Oaks: Sage.

Prison Reform Trust, 2009. Bromley briefings. Prison factfile. London.

Prison Reform Trust, 2011. Bromley briefings. Prison factfile. London.

Quraishi, M., 2008. Researching Muslim prisoners. International Journal of Social Research Methodology, 11 (5), 453-467.

Rutherford, M. \& Duggan, S., 2009. Meeting complex health needs in prison. Public Health, 123 (6), 415-418.

Ryan, G.W. \& Bernard, H.R., 2003. Techniques to identify themes. Field Methods, 15 (1), 85-109.

Schlosser, J.A., 2008. Issues in interviewing inmates. Navigating the methodological landmines of prison research. Qualitative Inquiry, 14 (8), 1500-1525.

Scriven, A., 2012. Partnership, collaboration and participation: fundamental principles in a settings approach to health promotion In Scriven, A. \& Hodgins, M. eds. Health promotion settings: principles and practice. London: Sage, 17-34.

Senior, J. \& Shaw, J., 2007. Prison healthcare. In Jewkes, Y. ed. Handbook on prisons. Cullompton: Willan Publishing, 377-398.

Smith, C. \& Wincup, E., 2002. Reflections on fieldwork in criminal justice institutions. In Welland, T. \& Pugsley, L. eds. Ethical dilemmas in qualitative research. Aldershot: Ashgate, 108-120. 
St Leger, L., 1997. Health promoting settings: Form Ottawa to Jakarta. Health Promotion International, 12 (2), 99-101.

Stewart, D., 2008. The problems and needs of newly sentenced prisoners: Results from a national survey. London.

Tobbell, J. \& O’Donnell, V.L., Year. Theorising educational transitions: communities, practice and participationed. eds. Socio-Cultural Theory in Educational Research and Practice Conference, Manchester.

Whitehead, D., 2006. The health promoting prison (hpp) and its imperative for nursing. International Journal of Nursing Studies, 43 (1), 123-131.

Who, 1986. Ottawa charter for health promotion. Health Promotion, 1 (4), iii - v Available from: http://heapro.oxfordjournals.org/cgi/content/abstract/1/4/405

Williams, N.H., 2007. Prison health and the health of the public: ties that bind. Journal of Correctional Health Care, 13 (2), 80-92.

Willmott, D. \& Van Olphen, J., 2005. Challenging the health impacts of incarceration: the role of community health workers. Californian Journal of Health Promotion, 3 (2), $38-48$.

Woodall, J., 2010. Control and choice in three category-c English prisons: Implications for the concept and practice of the health promoting prison. Unpublished PhD thesis. PhD. Leeds Metropolitan University.

Woodall, J. \& South, J., 2012. Health promoting prisons: Dilemmas and challenges. In Scriven, A. \& Hodgins, M. eds. Health promotion settings: principles and practice. London: Sage, 170-186. 